\title{
Poblamiento y desarrollo de enclaves turísticos en la Norpatagonia chileno-argentina. Migración y frontera en un espacio binacional ${ }^{1}$
}

\author{
Hugo Marcelo Zunino², Brenda Matossian ${ }^{3}$ y Rodrigo Hidalgo ${ }^{4}$
}

\begin{abstract}
RESUMEN
Se ofrece una lectura del proceso de crecimiento demográfico de la Norpatagonia chileno-argentina, especialmente enfocado en las migraciones entre 1980 y 2002. Se busca asimismo realizar este análisis dentro de un contexto de las relaciones binacionales entre ambos Estados. De modo de adquirir una visión multidimensional y no reduccionista del fenómeno, consideramos elementos provenientes tanto de procesos históricos como de las estructuras sociales presentes a uno y otro lado de la cordillera, en el entendido que los ecos temporales y las coyunturas sociales y políticas definen -en parte- las posibilidades y restricciones para la movilidad de los individuos. Los resultados muestran una fuerte migración chilena hacia Argentina durante la época más álgida de la dictadura militar de Augusto Pinochet, periodo durante el cual la migración laboral y especialmente aquella por razones políticas cobran relevancia. En la década del noventa el crecimiento poblacional se concentra en los departamentos argentinos y comunas chilenas que presentan los mayores recursos turísticos. En muchos de estos casos la migración no es solo laboral, sino compuesta en parte importante por migrantes de amenidad o por estilos de vida. En la parte final reflexionamos sobre el nexo existente entre capitalismo en crisis, la actividad turística, y sugerimos algunas líneas futuras de investigación.
\end{abstract}

Palabras clave: Poblamiento, Patagonia, Argentina, Chile, estructura social.

\begin{abstract}
This work is aimed at offering a reading of the occupation of the nor-Patagonia region between the years 1980 and 2002. To advance a multidimensional and non-reductionist analysis of the process we consider both, historical processes as the social structure in place at both sides of the Andes Mountain Range; acknowledging that the temporal echoes and the social and political conjunctures define - in important ways - the possibilities and restriction for the mobility of individuals. The results show that a strong migration of Chileans to Argentina took place even in the most algid moments of the dictatorship of Augusto Pinochet; period in which labor migration and foremost that linked with political repression acquire relevance. During the 90's population increase concentrated in the Argentina's departments and Chile's municipalities which concentrate tourist resources. In many cases migration is not just for work reasons but also composed to an important extent of amenity and lifestyle migrants. In the last section, we consider the existing links between capitalism in crisis, tourist activity, and suggest some futures lines of research.
\end{abstract}

Key words: Occupation, Patagonia, Argentina, Chile, social structure

\footnotetext{
1 Este artículo es resultado parcial del proyecto FONDECYT 1100588-Componente Cooperación Internacional. El trabajo de colaboración se continuó y profundizó en el marco del proyecto FONDECYT 1120589 (2012-2014). Artículo recibido el 8 de enero de 2012, aceptado el 13 de julio de 2012 y corregido el 5 de septiembre de 2012.
}

2 Departamento de Ciencias Sociales, Universidad de La Frontera (Chile). E-mail: hzunino@ufro.cl

3 Instituto Multidisciplinario de Historia y Ciencias Humanas Consejo Nacional de Investigaciones Científicas y Técnicas (Argentina).

E-mail: bmatossian@gmail.com

4 Instituto de Geografía, Pontificia Universidad Católica de Chile (Chile). E-mail: hidalgo@geo.puc.cl 
A partir del estudio del crecimiento demográfico registrado en las comunas chilenas y departamentos argentinos, comprendidos en el área de estudio, este trabajo apunta a ofrecer una lectura general sobre el proceso de poblamiento entre 1980 y 2002 de la Norpatagonia chileno-argentina, poniendo atención a los principales movimientos migratorios internos y transfronterizos que nos permitan comprender la dinámica poblacional en contextos históricos y sociopolíticos determinados. Dicho contexto lo entendemos ligado a cambios en las estructuras sociales, definidas como un conjunto de reglas en constante transformación a través del tiempo. Son estas estructuras las que enmarcan los procesos sociales y demográficos, posibilitando o restringiendo la movilidad de los individuos (ver Giddens, 1984). En efecto, tanto las condiciones políticas, económicas como las nuevas formas de poblar el territorio, surgidas al alero de la llamada sociedad "postindustrial", tienen efectos directos en los lugares de acogida de los migrantes tanto internos como externos. La Figura 1 muestra el área de estudio, la cual queda definida por los departamentos de sectores fronterizos de las provincias argentinas de Neuquén, Río Negro y norte de Chubut y las comunas fronterizas o que son riberanas a los grandes lagos del sur de Chile (regiones de La Araucanía, Los Ríos y Los Lagos).

Cabe consignar que quedan fuera de los límites de esta comunicación el examen detenido de los procesos de poblamiento que se desenvuelven en la microescala y de los factores concurrentes en las decisiones migratorias particulares. Un factor que realza el alcance e impacto de esta investigación es que, justamente, esta sentará las bases para futuras investigaciones que tengan por eje examinar casos particulares en cuanto a crecimiento poblacional, flujos migratorios y consecuencias socioculturales en áreas de fronteras del sur del continente americano. Así, son varios los elementos que particularizan a este estudio.

Primero, una aproximación clásica a la noción frontera nos convoca a considerarla como un espacio en el que se desarrollan múltiples conflictos, donde la direccionalidad de los flujos ostenta tensiones de muy distintas intensidades. Siguiendo a País (2011), las fronteras son representaciones construidas en el campo de la disputa económica, política y simbólica. Este espacio es en realidad poroso y está teñido por una permanente y variable tensión entre lo local, lo regional, lo nacional e internacional en sus relaciones cotidianas. Dichas tensiones reflejan intereses, negociaciones, complicidades y conflictos visibles pero también en muchos casos invisibilizados. El caso particular de la frontera entre Chile y Argentina es un ejemplo claro de conflictos limítrofes que han cruzado la historia de ambas naciones. Sin embargo, desde nuestra perspectiva, incluso en situaciones de conflicto, la frontera puede mantener una porosidad que va más allá del desencuentro entre ambas naciones y que es parte de un rico intercambio entre países fronterizos; como lo han demostrado distintas investigaciones (ver, por ejemplo, Canales, 2002; Ramos, 2002; Durand y Massey, 2003; Santos, 2004; Alegría, 2011).

Hasta ahora, un reducido número de estudios han abordado investigaciones con una clara perspectiva binacional, como el análisis de las dinámicas fronterizas entre los asentamientos de Trevelin (Argentina) y Futaleufú (Chile) por Baeza $(2007,2009$ y 2011), y la comparación turística, arquitectónica y urbanística entre San Carlos de Bariloche y Osorno, Puerto Montt y Puerto Varas, analizada por Lolich et al. (2001). En un ámbito similar, en el área de la conformación de los discursos fronterizos y con un fuerte componente teórico, destacamos también las aportaciones de Núñez para la frontera surpatagónica (2011a, 2011b). Desde una perspectiva histórica cabe considerar el trabajo de Méndez (2005) sobre la importancia del eje San Carlos de Bariloche - Puerto Montt.

En segunda instancia, es relevante consignar que, a pesar de que la Norpatagonia andina ha mantenido un significativo dinamismo transfronterizo y presenta recursos económicos de altor valor que podría sentar las bases para un desarrollo binacional integral (potencial ganadero, hidroeléctrico y turismo, por nombrar solo algunos), no existen estudios escolásticos de largo alcance que apunten a generar planes y estrategias de acción concreta para el desarrollo de un espacio que representa, desde el punto de vista natural, una unidad que trasciende los límites políticos. La sistematización de información 
Figura $\mathrm{N}^{\circ} 1$

Área de Estudio: Norpatagonia chileno-argentina

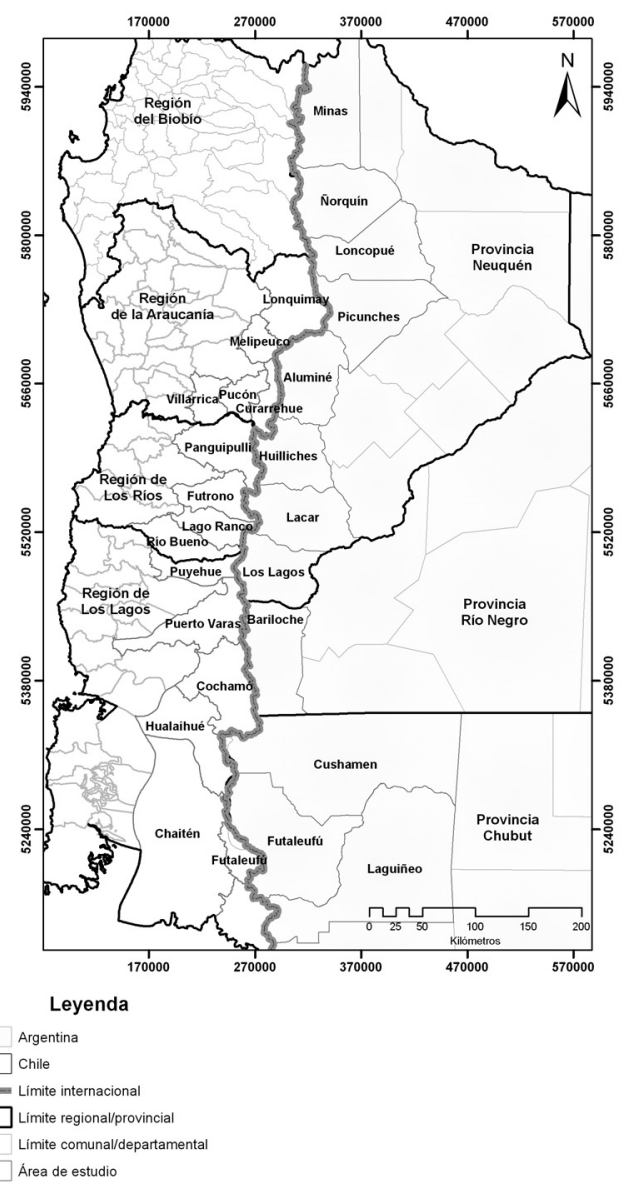

Fuente: Elaborado en base a datos obtenidos de Instituto Geográfico Militar (Chile), Instituto Geográfico Militar (Argentina) y censos nacionales de población de Chile y Argentina.

a nivel de la macroescala sobre la dinámica poblacional transfronteriza, constituye un primer paso indispensable para avanzar tanto en estudios de situaciones puntuales, como en la formulación de estrategias de desarrollo.

En tercer lugar, desde una esfera teóricaconceptual, se presta debida atención a la dialéctica entre las estructuras sociales y los procesos migratorios, asumiendo las posibilidades y restricciones que impone la macroestructura sociológica en la movilidad de bienes y personas.

Este trabajo se organiza como sigue. En la siguiente sección desarrollaremos el marco teórico que sustenta esta investigación, poniendo especial atención en la noción de "estructura social" y a cómo esta restringe y posibilita la movilidad de los individuos. Enfatizaremos el carácter social del proceso de formación de la "estructura" y su continua reproducción a través de la cotidianeidad diaria de los individuos, construcción teórica que permite relacionar de manera no determinista el contexto estructural con el movimiento de la población (Giddens, 1984).

En el tercer apartado, presentaremos la metodología seguida para examinar los procesos de poblamiento en el período bajo escrutinio. Al inicio expondremos los métodos utilizados para interpretar y describir las estructuras sociales presentes en Chile y Ar- 
gentina en distintos períodos de tiempo y su impacto sobre flujos transfronterizos. Seguidamente, describiremos los procedimientos utilizados para examinar los datos cuantitativos que ofrecen los censos de población de ambos países. En base al cruce de esta información llegaremos a distintos contextos históricos-estructurales aparejados a ciertos patrones de movilidad.

En el cuarto acápite desarrollaremos los argumentos en base a una distinción de las condiciones estructurales -con especial atención a las condiciones políticas y económicas- imperantes en distintos períodos de tiempo en Chile y Argentina, lo cual relacionaremos con movimientos migratorios, crecimiento poblacional y porcentaje de población extranjera en relación al total en la comuna o departamento respectivo. En similar línea inquisitiva, identificaremos particularismos geográficos, que escapan de la norma general, los cuales requieren un tratamiento más detenido y que han sido foco de recientes investigaciones. La sección final sintetiza los resultados alcanzados y sugiere nuevas líneas de investigación.

\section{Estructura, la libertad del individuo y los procesos migratorios}

El poblamiento del territorio constituye el fundamento para comprender las transformaciones espaciales, sociales, culturales y/o económicas de un área particular. El poblamiento de un espacio geográfico está relacionado con las dinámicas demográficas generales y -por cierto- con los movimientos migratorios internos y externos, los cuales, a su vez, están influidos por el contexto socioeconómico que opera a escala global, pero que impacta sobre distintas escalas geográficas interconectadas (Swyngedouw, 1997). Este planteamiento apunta a concebir la "estructura" no como un conjunto de normas que actúan de manera rígida y determinista, sino como una serie de reglas sociales creadas por individuos que defienden intereses (Giddens 1984, Zunino 2006a). Tomando en consideración este constructo teórico, se colige que las estructuras son plásticas y moldeables en el espacio-temporal, dado que las reglas que las conforman pueden ser recreadas o sustituidas por otro conjunto de reglas. Las reglas sociales imperantes actúan en distintos niveles funcionales, incidiendo en aquellos que toman decisiones a nivel nacional hasta las decisiones del individuo y/o conglomerados de individuos que toman decisiones que afectan profundamente su rutina diaria y calidad de vida; este es el caso de la elección del lugar de residencia.

Este planteamiento es consistente con la "Teoría de la Estructuración" desarrollada por Giddens (1984). Para este autor, a diferencia de las posiciones marxistas, las estructuras sociales no son solo coercitivas, sino que ofrecen oportunidades para la acción social colectiva y para desafiar directrices derivadas del centro. Así, por ejemplo, por muy autoritario que sea un gobierno y el control de frontera estricto, grupos de individuos retienen la posibilidad de migrar ya sea legal o ilegalmente buscando escapar de la represión (migración política) o mejores condiciones laborales (migración clásica). En este contexto, la noción de "agente estructurado" reconoce un aspecto clave de la vida cotidiana: ninguna organización o individuo tiene el control absoluto, dado que estamos en presencia de reglas sociales (no naturales) que son moldeadas e interpretadas por individuos que son, al menos, parcialmente libres. Esto no desconoce la existencia de estructuras generales de dominación. El punto de Giddens, es que siempre hay fisuras institucionales que es posible aprovechar para avanzar en la consecución de fines determinados (ver también Zunino, 2006a).

Siguiendo a Giddens, las fronteras pueden considerarse espacios de contacto en donde un conjunto de reglas definen las posibilidades y restricciones que enfrentan los flujos entre dos naciones. Pero estos flujos distan de ser estáticos y la porosidad está relacionada con el conjunto de reglas que imperan en un espacio-tiempo determinado. Así, la ocupación del espacio geográfico se enmarca en la dinámica de los procesos sociales y económicos que se han desenvuelto durante toda la historia humana a escalas más generales. La época "fordista" o "industrial" estuvo marcada por el crecimiento del sector secundario y de las grandes ciudades, situación que en Chile y en Argentina se aprecia en el crecimiento poblacional de las principales áreas Metropolitanas y Capitales Regionales/Provinciales (Aguirre, 2009). En Chile, estos espacios 
nodales para el funcionamiento del sistema económico se convirtieron en receptores de migrantes en busca de fuentes de trabajo, proceso que hasta ahora se mantiene en vigor (Arroyo, 2000). Similarmente, Argentina es un país de temprana y profunda urbanización. En la historia de la conformación del territorio, las migraciones del campo a la ciudad habían constituido un aporte de relevancia dentro del territorio nacional, sobre todo desde la década del cincuenta, cuando comenzaron a sumarse poblaciones rurales a las periferias de las principales ciudades, proceso que aún no se ha detenido y se reproduce activamente en las principales ciudades de todo el país (Sassone et al., 2010).

Actualmente, se ha constatado una gradual e incipiente "migración inversa": desde de una migración campo-ciudad (urbanización clásica) hacia un movimiento desde los espacios urbanos a la periferia de ciudades y comunas rurales; procesos demográficos que Ferrás (2000) y Arroyo (2001) asimilan con movimientos centrífugos que marcan un contrapunto con los movimientos centrípetos de la época industrial. Se generan así nuevas formas de poblar el territorio, como el incremento de la población en suburbios y áreas rur-urbanas, dando forma a la ciudad dispersa con límites cada vez menos definidos (Monclús, 1998; Vidal Koppmann, 2007; Zunino e Hidalgo, 2009). Paralelamente, en especial a partir de la década del noventa, se registran también procesos de cambio intensos en los cinturones hortícolas de las grandes ciudades donde se produce una reconfiguración y complejización del periurbano con un consecuente relocalización del cinturón verde hacia áreas más alejadas (Barsky, 2005; Salazar y Osses, 2010).

Esta dinámica socioeconómica ha impactado fuertemente al ámbito rural provocando lo que se ha denominado la "tercerización del espacio rural", marcada por la pérdida de importancia de la agricultura tradicional y el surgimiento de nuevos polos de crecimiento económico, los cuales se puede ejemplificar en clusters turísticos y centros de innovación tecnológica (Pérez, 2001; Bardají et al., 2008). Comienzan, así, a generarse nuevas e incipientes interacciones de personas, capital y recursos entre el mundo urbano y el mundo rural (Allen et al., 1999; Allen, 2003).
Esta terciarización de lo "rural" se ha asociado a la era postindustrial y nuevas formas de poblar el territorio. Así, la literatura sobre migración de amenidad pone el acento analítico en la migración de personas desde las metrópolis a ciudades pequeñas o pueblos rurales en el interior, sobre todo hacia destinos de montaña, cuya calidad ambiental y cultural es percibida como superior a la de sus lugares de residencia anteriores (Moss, 2005, 2006; González et al., 2009; Hidalgo et al., 2009). Otro cuerpo teórico que ayuda a comprender las migraciones en la época postindustrial es aquella referida a la migración por estilo de vida. O’Reilley (2000) describe aquella relocalización como producto de una actitud reflexiva de los individuos sobre sus propias vidas y las posibilidades que el migrante visualiza en la comunidad receptora, por ejemplo: una vida relajada y tranquila, gastos más bajos en vivienda, clima, beneficios para la salud, y sentimiento de vivir en comunidad. Detrás de esta perspectiva está la creencia que hay oportunidades para una vida mejor en otro lugar. Sin duda esta aproximación, fuertemente influida por la psicología y sociología, puede ayudarnos a comprender las movilidades que caracterizan a la sociedad postindustrial.

Las consideraciones anteriores denotan que la ocupación del territorio está íntimamente relacionada con procesos sociales, económicos y políticos que se desenvuelven a escalas más generales. Lo anterior se relaciona directamente con las distintas fases de ocupación de los espacios donde se materializan las situaciones descritas. Es del todo necesario precisar que no nos estamos refiriéndonos a situaciones lineales; en efecto, la mentada sociedad postindustrial en los países periféricos comparada con los centros de comando y control capitalista se desenvuelve en forma altamente selectiva, y solo algunos lugares se ven afectados por migraciones de tipo no laboral como por migración de amenidad o migración por estilos de vida. Es precisamente este razonamiento el que nos lleva a preguntarnos si en el área de estudio las migraciones de amenidad o por estilos de vida desenvuelven o no un papel en la reconfiguración del territorio transfronterizo de la Norpatagonia, que se analiza en este trabajo. 
En este contexto, afirmamos que las dinámicas demográficas, en general, y las migraciones, en particular, se ven afectadas por acontecimientos que derivan de las estructuras sociales presentes en Chile y Argentina, las que a su vez posibilitan o restringen un particular tipo de migración. El constructo metodológico se sustenta entonces en examinar las estructuras sociales que enmarcan la movilidad en determinados contextos históricos, para luego pasar a analizar e interpretar los datos censales asociados a las situaciones planteadas.

\section{El estudio de las estructuras sociales y las limitaciones de las fuentes censales en estudios comparativos}

Siguiendo los trabajos de Giddens, 1984; Ostrom, 1986; Zunino 2006a, 2006b, 2006c; Zunino e Hidalgo, 2009 y 2011, las estructuras sociales serán concebidas por un conjunto de reglas sociales escritas (formales) y no escritas (informales, como las convenciones sociales) que establecen las posibilidades y restricciones para la acción y decisión social, como lo es la decisión de migrar. Dado que la lectura de la constelación de leyes que inciden en el comportamiento de los individuos es difícil de leer en su totalidad, por economía académica hemos seleccionados solo algunas reglas sociales de las 9 definidas por Ostrom (1986). Cualquier intento por leer en su totalidad la constelación de reglas sociales redundaría en un bosquejo matemático del comportamiento social, en un funcionalismo que dado la "plasticidad" de las reglas sociales resultaría necesariamente limitado y reduccionista.

Entre las reglas sociales que identifica Ostrom (1986), dado el alcance y temporalidad del estudio nos parece relevante examinar: (a) la capacidad que los individuos tienen para modificar los resultados de un proceso de toma de decisiones (reglas de alcance); (b) las medidas que una posición o cargo es capaz de imponer (reglas de autoridad); y (c) los mecanismos utilizados para tomar decisiones colectivas (reglas de agregación). Estas tres reglas permitirán una lectura sistematizada del contexto estructural en ambas naciones, abriendo también las puertas para examinar las estrategias desplegadas para avanzar hacia determinados fines.

En el estudio de las estructuras sociales, los datos estadísticos conforman una fuente de información de indiscutido valor, constituyendo una herramienta de análisis indispensable en las ciencias sociales. Independiente de sus limitaciones, los resultados de ese análisis dan un contexto relacional y no discrecional a las relaciones que establecen los distintos niveles y diálogos entre los agentes comprometidos en el diagnóstico que establecen las reglas de Ostrom (1986).

En todo caso, se debe considerar también las limitaciones analíticas que implica el uso del dato estadístico por el hecho de respaldar el número o cifra resultante, en especial al utilizarlas como ejes de periodización. Torrado (1992: 39) afirma al referirse a los períodos de estudio que "el criterio con que acotamos nuestro período de observación ha sido exclusivamente teórico, porque deseamos diferenciarnos de una práctica desdichadamente usual en la investigación social: la de periodizar la historia en función de las fuentes de información disponibles". Y continúa: "esta práctica, de neta filiación empirista, no tiene en cuenta que la fecha de recolección de un dato (por ejemplo, el año de realización de un censo de población) responde más a criterios de orden técnico que al deseo de establecer hitos de información relevantes para la construcción de la historia social de un país". Esta aclaración nos alerta sobre la necesidad de indagar los fenómenos sociales desde una perspectiva abierta, considerando las fuentes estadísticas en su contexto histórico y con un marco teórico definido; en la línea que fue señalada en el párrafo anterior. Así, nuestra concepción parte de rescatar el valor de los datos censales como elementos de estudio de una realidad social que los trasciende y con ello se hace necesario establecer un diálogo entre los números y el contexto social.

Si bien se estudia un período comprendido entre los años 1980 y 2002 según tres censos nacionales levantados (1980, 1991 y 2001 para el caso argentino, y 1982, 1992 y 2002, para el chileno), se dedica una debida atención a los contextos histórico-políticos previos, los cuales, junto con importantes es- 
tudios de antecedentes, justifican la relevancia de estas dos décadas en el crecimiento poblacional de esta región binacional.

Los datos estadísticos analizados se refieren a los totales de población para cada una de las unidades espaciales en cada uno de los censos nacionales. A partir de dichos datos se calcula el crecimiento intercensal con miras a detectar aquellos sectores que han mostrado los crecimientos más acelerados en esta región binacional. Además, se analizará la proporción de extranjeros sobre el total de población para distinguir aquellas áreas donde el aporte migratorio internacional ha signado el proceso de poblamiento. Así se busca dar cuenta de distintos elementos que permiten distinguir las modalidades del crecimiento demográfico y de la distribución espacial de la población en la Norpatagonia andina argentino-chilena.

\section{Migración y ocupación del territorio}

\section{Una región, dos Estados nacionales: un contexto histórico necesario}

Argentina y Chile comparten la tercera frontera terrestre más larga del mundo (5.150 kilómetros). Este dato, que puede parecer superficial, da cuenta de una cantidad y variedad de lugares que representan en sus distintas escalas diferentes realidades territoriales. Es así como existen complejas relaciones y vínculos que han unido y distanciado a ambos países a lo largo de su historia como EstadosNación y como vecinos. Es aquí en donde cobra particular fuerza la noción frontera como espacio de conflicto, tensiones y también de intercambio y diálogo social y cultural. En este último sentido, es que incluso en situaciones de conflicto los flujos fronterizos se mantienen a pesar de las dificultades, lo que cambia es el conjunto de posibilidades y restricciones para traspasar frontera. Una frontera al estilo de una "barrera" puede darse, efectivamente, solo en situaciones determinadas y localizadas en el espacio y tiempo, como puede ser un conflicto armado o el cierre de una frontera por razones económicas o étnicas.

La frontera, entonces, la entendemos no solo como un lugar de conflicto, sino que también ella se concibe como un espacio de encuentro e intercambio. De allí surge el desafío teórico y metodológico que pretende comparar oportunidades y restricciones que han enfrentado los movimientos migratorios entre ambas naciones entre los años 1980 y 2002, en el caso de este estudio, pero que está totalmente presente hoy al 2012. En esta línea, Bandieri (2005: 15) propone derribar como límite del conocimiento a la noción de frontera instituida entre los respectivos Estados nacionales, en este caso Argentina y Chile, "en el convencimiento de que resulta imposible cualquier aproximación comprensiva a la historia regional si no se recupera fuertemente la idea de que las áreas fronterizas no funcionaron como límites, sino como verdaderos espacios sociales de gran dinamismo y alta complejidad". En este sentido, dentro de la región bajo análisis, se ha mantenido una fuerte circulación de bienes, servicios y personas a uno y a otro lado de la cordillera desde tiempos previos a la conformación de los Estados-Nación. En similar línea inquisitiva, Zusman (2006: 183) señala que la geografía histórica reciente concibe las fronteras como "lugares construidos en el marco de las políticas coloniales/estatales, y no una consecuencia espontánea del proceso de ocupación"; lo cual sugiere que la relativa porosidad fronteriza depende de contextos sociohistóricos definidos.

En este punto cabe realizar una aclaración en cuanto a las escalas de análisis. En este sentido, retomamos la noción de la doble dimensión de la escala: como ámbito de ocurrencia de un fenómeno y como estrategia de aprehensión de la realidad. Se conciben así las escalas como construcciones deliberadas para abordar una realidad relacional y expresiones de la organización de los procesos sociales. Es la política la mediadora material y simbólica del poder en el territorio, siendo el Estado nacional el actor de mayor peso aunque también intervengan otras organizaciones públicas y privadas de ámbitos intermedios y locales (Navarro Floria y DelRío, 2011). Es en la escala nacional en la cual se constituyen las tensiones y conflictos más resonantes entre Chile y Argentina y es por ello que nos dedicaremos a analizarlas desde esta perspectiva en este apartado. Sin embargo, esto no nos hace perder de vista que el área de estudio se encuentra sujeto 
a complejas lógicas atravesadas simultáneamente tanto por el poder hegemónico central y global, como por aquellas relaciones regionales; tal como proponen Méndez y Tozzini (2011: 165): "existe una necesidad de estudiar la región en conexión con las historias múltiples de ambos lados de la cordillera".

Considerando estos elementos, se hace necesario en esta instancia, comprender la estructura social en determinados lapsos temporales, como las tensiones diplomáticas entre ambos Estados y sus vaivenes como elementos que contextualizan y, en cierta medida, explican el crecimiento demográfico y la movilidad de la población.

Si bien las relaciones bilaterales se mantienen desde hace décadas con una línea colaboracionista, los períodos de conflicto a lo largo de 200 años de historia compartida han dejado tensiones más o menos latentes en el desarrollo de esta región. Sin intentar exhaustividad, es necesario remontarnos a los episodios y conflictos más significativos entre ambos países que contribuyeron a agregar elementos tensos a esta relación. Ya desde los tiempos en los cuales se definieron los territorios nacionales de ambos países, se presentaron diferencias para demarcar espacios soberanos. La Patagonia es un primer escenario y al tiempo que se firma el Tratado de Chile con la Corona Española sobre Paz y Reconocimiento (1881), ya se recibe un primer reclamo argentino (Fuentes Lazo, 2007: 52).

Las tensiones a raíz del tratado de 1881 , en el cual se fijaba como límite hasta el paralelo $52^{\circ}$, la cordillera de los Andes, por las altas cumbres que dividían las aguas, culminaron en 1902 con los denominados "Pactos de Mayo" y la aceptación de las condiciones que resolvía el laudo arbitral británico. Esta situación de consenso se mantuvo vigente durante medio siglo aproximadamente (Lacoste, 2001; Cabrera, 2008). Décadas más tarde, en 1959, los presidentes Arturo Frondizi y Jorge Alessandri firmaron en Santiago la "Declaración de Cerrillos", donde prevalecen conceptos sobre la necesidad de cuidar la paz y respetar a la soberanía de los Estados. Meses después de la declaración se acuerda someter a la jurisdicción de la Corte Internacional de Justicia de La Haya la cuestión del Canal Beagle (Fuentes Lazo, 2007). Sin embargo, las tensiones por la cuestión del Beagle se iban haciendo cada vez más intensas. Finalmente se conoció el laudo arbitral de 1977, el cual, a comienzos de 1978, Argentina declaró como nulo, mientras que Chile reiteró la plena validez y necesaria aplicabilidad del mismo. En un clima de constante tensión, que casi Ileva a un enfrentamiento bélico a ambos países, el 8 de enero de 1979 se logró firmar el Acta de Montevideo, en que las Partes, de común acuerdo, solicitaban la Mediación Vaticana. Esta mediación, aunque no sin dificultades, llevó a ambos países a suscribir el Tratado de Paz y Amistad de 1984. Con eso se superaba la crisis más seria en la relación de vecindad chileno-argentina (Matossian, 2010).

En ciertos sectores de ambas naciones se mantuvo la tensión en la década de los ochenta y las reglas sociales imperantes estructuraban sociedades autoritarias, donde prevalecieron las decisiones de las cúpulas político-militares (reglas de alcance y autoridad), y la participación ciudadana se vio severamente limitada llegando a una represión brutal de todo movimiento contrasistémico. En este contexto, se podría esperar encontrar una "frontera porosidad opaca" con bajos niveles de flujos migratorios. Sin embargo, se debe ampliar la mirada de este contexto histórico tan particular y apreciar que si bien existían limitaciones para el tránsito transfronterizo, esto no significó la presencia de una barrera sólida inexpugnable.

Resulta imprescindible resaltar la crisis económica chilena de los años ochenta, dada la puesta en marcha de drásticas medidas económicas de corte neoliberal. Para Zunino e Hidalgo (2011), las radicales reformas neoliberales iniciadas por el gobierno autoritario (1973-1990) y continuadas con más sutileza por los gobiernos democráticos (1990 - presente) no apuntaban tan solo a la esfera económica, buscaban cambiar integralmente a Chile, y en gran parte consiguieron este objetivo. En un nivel general, este proyecto mesiánico transformó la mentalidad de los ciudadanos en términos de la forma de entender los problemas y cómo de encarar su resolución. Se ha pasado desde el "sujeto político" que intentaba la acción colectiva como herramienta para alcanzar sus fines hacia una radical individualización, en donde el accionar del sujeto y sus decisiones están basadas 
en una estricta racionalidad económica. Así, en la década de los ochenta, se plantea una contradicción entre el modelo neoliberal que impulsa la libertad económica individual (que está sustentada por la movilidad de la fuerza de trabajo) y la mentalidad militarista dictatorial imperante en la década de los ochenta y que pone trabas a la movilidad de los ciudadanos.

En Argentina, distintos gobiernos de facto se sucedieron con anterioridad a la década del setenta, a diferencia del caso chileno. Sin embargo, a los fines de este trabajo interesa destacar las particularidades del último gobierno dictatorial. En 1976, una sublevación militar derrocó a la presidenta María Estela Martínez de Perón, instalando una dictadura de tipo Estado burocrático autoritario (O'Donnell, 1982) autodenominada Proceso de Reorganización Nacional, gobernada por una junta militar integrada por tres militares, uno por cada fuerza. A diferencia del "modelo chileno", dicho proceso no estuvo tan profundamente y directamente asociado a la penetración neoliberal, la consolidación de ese diseño se fue dando de modo más gradual a través de la sucesión de gobiernos dictatoriales y luego democráticos, con especial y dramática profundidad en la década de los noventa.

Retomando el período 1976-1983, para el caso argentino el esquema de desarrollo aperturista estaba basado en un disciplinamiento social generalizado y un cambio drástico de la antigua estructura de relaciones económicas, sociales y políticas de los modelos desarrollista (1958-1972) y justicialista (1945-1955) que lo precedieron (Torrado, 1992). De allí que la estrategia fue la apertura externa de la economía, generando un momento de gravedad económica entre 1980 y 1982. En este contexto, la guerra de las Malvinas que enfrentó a Argentina con el Reino Unido (1982), junto a la represión y corrupción, provocaron la caída de la junta militar, y meses más tarde la cuarta junta llamó a elecciones para el 30 de octubre de 1983, en las que triunfó el candidato de la Unión Cívica Radical, con Raúl Alfonsín (1984-1989). Este gobierno se encargó de impulsar la complicada consolidación institucional democrática luego de largos años de dictaduras. Sin embargo, el impulso progresista se detuvo pronto ante los sindicatos, que resistían ser reformados; la Iglesia, que peleó en el terreno del laicismo; y las Fuerzas Armadas, que toleraron el juzgamiento de sus antiguos jefes retirados (el Juicio a las Juntas fue el logro más importante de la civilidad), pero resistieron el juzgamiento de oficiales en actividad (Romero, 2003). En lo económico, con buena parte del aparato productivo quebrado y una deuda externa en aumento, Alfonsín decidió aplicar en 1985 un plan económico, el Plan Austral, que él mismo calificó como "economía de guerra". Los graves problemas económicos se expresaron en una tasa de inflación de 343\% para el año 1988 y el estallido de un proceso hiperinflacionario a partir de febrero de 1989, superior al $3.000 \%$ anual, que hizo aumentar la pobreza.

Sin embargo, en Chile, la imposición del modelo hegemónico neoliberal actual, imperante hoy en gran parte de América Latina, no fue inmediato luego del golpe de Estado en 1973 , sino que fue un proceso y solo a fines de la década de 1970, se manifiestan de modo decidido en el diseño y construcción de políticas de Estado los principios de la desregulación, privatización y mercantilización de la economía que apuntaron a la libre competencia y a que las actividades productivas y generadoras de renta se rigieran por las fuerzas del mercado. En este sentido, la experiencia chilena, bajo un régimen autoritario, ha sido ampliamente reconocida como un verdadero laboratorio para el resto del continente y también para las reformas que se llevaron a cabo en los gobiernos de Tatcher en Inglaterra y de Reagan en Estados Unidos a inicios de la década de 1980 (Harvey, 2007), ello fue denominado en esos años como el "milagro económico chileno" (ver Valdés, 1995).

En Argentina, los gobiernos de Carlos Saúl Menem (1989-1995 y 1995-1999) establecieron la paridad 1 a 1 entre los valores de la moneda nacional y del dólar estadounidense. De esta manera, se reduciría el aumento de precios vinculado a la importación de insumos. Inspirado en la experiencia chilena, privatizó numerosas empresas, algunas de ellas monopolizadoras de los servicios de electricidad, agua, gas, combustible, correo, transporte y telecomunicaciones. El segundo gobierno de Menem (1995-1999) estuvo caracterizado por el aumento de los indicadores negativos, 
como el desempleo, la pobreza y el trabajo precario no registrado. Además, la deuda externa aumentó en casi 82.000 millones de dólares. Dichos indicadores se agravarían con el transcurso de los años, dando inicio en 1998 a un período de recesión económica que duraría más de 4 años. Como bien logra sintetizar Romero (2003: 101): "si el fantasma del Proceso sustentó la democracia, el fantasma de la hiperinflación sostuvo largamente la Convertibilidad".

En ambos países las dictaduras estuvieron marcadas por agudas crisis económicas, sociales y políticas. Para el caso argentino, la democracia no logró las mejoras esperadas en el plano económico, sino una profundización del modelo de desarrollo aperturista y de las políticas económicas neoliberales. En ambos casos, aún con temporalidades e intensidad particulares, estas crisis tuvieron su origen en la destrucción del aparato productivo nacional y en una marcada desarticulación institucional. En términos de reglas sociales, ambos países se enfrentaron a un contexto estructural donde dominó el alcance y la autoridad de los que detentan el poder político y económico, en la concentración del poder y en un marcado centralismo. En el Chile de los noventa las reglas sociales imperantes muestran una gradual dispersión del poder (democracia "protegida"), junto con un aumento de la capacidad y alcance de los actores sociales para ejercer influencia en la toma de decisiones. Surge una nueva sociedad, marcada por una mejora general en las condiciones de vida, ansias de renta inmediata, altos niveles de endeudamiento y el surgimiento de una clase media aspiracional. En Argentina, en cambio, una vez pasada la "primavera democrática" y las desilusiones que trajo en el plano económico, la sociedad mantuvo una actitud indiferente y mostró una pragmática aceptación de las reglas del juego, que el discurso oficial presentaba como inapelables.

Una vez retornada la democracia en ambos países, fue posible la resolución de los problemas limítrofes que condicionaron durante siglo y medio la profundización de las relaciones bilaterales. Aun así, a lo largo de los años estas tensiones "generaron a ambos lados de la frontera sentimientos encontrados hacia el vecino -percepciones distorsionadas y negativas (como el expansionismo)-, los que en buena medida también fueron alimentados por la cultura nacionalista, las interpretaciones de los historiadores, los textos de geografía y la formación educativa y militar" (Bernal Meza, 2007: 20). Con todo, se puede argumentar también, que "apertura democrática" a ambos lados de la cordillera trajo consigo una reducción de las tensiones y la firma de acuerdos bilaterales que fueron factores favorables para la movilidad transfronteriza.

Poblamiento, tensiones y escala: transformaciones estructurales en Chile, efectos regionales y migración hacia Argentina

En cuanto al intercambio de población entre ambos países, cabe destacar que Argentina históricamente ha sido un polo de atracción con "mayor desarrollo relativo y superior calidad de vida y bienestar compartido" (Sassone, 1994:107). Asimismo se ha constituido como destino principal de la emigración chilena hasta principios de la primera década del siglo XX. Para 2003, el $80 \%$ de los chilenos en el exterior residía en Argentina (INE, 2005). Visto desde la temporalidad, estos intercambios han seguido una lógica estrechamente vinculada a los vaivenes políticos y económicos de cada uno de los Estados, aunque manteniendo ciertas particularidades regionales (Matossian, 2012). La década del setenta fue testigo de una mayor movilidad de población desde Chile hacia Argentina y se distingue no solo por una llegada de población chilena cuantitativamente superior, sino por los conflictivos contextos políticos en ambos países y las tensas relaciones geopolíticas entre ellos.

El flujo migratorio se intensificó como consecuencia del caos político y militar reinante en Chile por el golpe militar al gobierno de Salvador Allende, en 1973. Al respecto, Norambuena destaca que en esa nación "desde los primeros tiempos de la vida republicana la historia del país consigna situaciones individuales y colectivas de expulsiones motivadas por asuntos políticos, pero que jamás tuvieron la connotación de masividad del exilio político de los años setenta" (Norambuena, 2000:174). Así, contingentes de exiliados políticos de distintos estratos sociales, Ilegaron a distintos puntos de Argentina, principalmente por tierra. Además de las razones políticas, las cuestio- 
nes económicas también fueron un motivo de emigración: en 1975, Chile alcanzó niveles de desocupación cercanos al 25\% (Paredes, 2003). El proceso migratorio por razones políticas se mantuvo hasta mediados de la década de los ochenta, demostrando que a pesar de las reglas sociales imperantes dirigidas a limitar la movilidad, los individuos retienen un "libertad limitada" y son capaces de aprovechar las fisuras del sistema.

Estos elementos contribuyen a comprender las tensiones de fines de los setenta y principios de los ochenta desde un enfoque binacional. En el marco de una política de fronteras de seguridad territorial, las autoridades argentinas adoptaron criterios restrictivos en el otorgamiento de radicaciones definitivas a chilenos en relación con el conflicto limítrofe sostenido con el país vecino en la zona austral (Cfr. Mármora, 1984; Sassone, 1987; Sassone y De Marco, 1994). Sin embargo, a pesar de los intentos restrictivos, el flujo migratorio continuó durante este período, y una clara muestra de ello ha sido la alta efectividad de la amnistía puesta en marcha al retornar la democracia en 1984 (Sassone, 1987, 2002; Maguid, 1998).

Durante la primera mitad de la década de 1980, especialmente a partir de 1983, se produce un nuevo impulso en la llegada de población chilena. Además de las condiciones adversas ya mencionadas en Chile, el advenimiento de la democracia en Argentina en 1983 fue sin duda un atractivo para muchos chilenos.

Para la zona de estudio, cabe aclarar que no solo migrantes chilenos se asentaron en la Norpatagonia andina argentina, sino que la década del ochenta brindó un panorama atractivo desde lo laboral también a migrantes internos, provenientes tanto desde áreas rurales como desde las grandes ciudades de la pampa húmeda en búsquedas de ambientes más naturales donde residir (Sassone y De Marco, 1994; Kropff Causa, 2001; Bondel, 2008; Matossian, 2012).

Este recorrido histórico político nos ha permitido contextualizar y problematizar la situación sociopolítica y cultural de principios de los ochenta, cuando comienza nuestro análisis demográfico particular. A partir de la década de los noventa, especialmente en Chile, la situación estructural se ve modificada con su relativo auge económico, constituyendo el embrión de una situación que marcó una contramigración histórica en la Norpatagonia. Con la mayor tradición y experiencia en negocios y promoción del turismo de clases medias y superiores, algunos empresarios argentinos del sector ven oportunidades de negocios y llegan a establecerse en ciudades cercanas a volcanes y grandes lagos. Aprovechando las reglas institucionales y sociales que favorecen "nuevas movilidades", se produce un trasvasije de su mayor desarrollo en las actividades de ocio y recreación casi propias de sociedades desarrolladas.

En la Norpatagonia, a partir especialmente de la migración de amenidad y por estilos de vida hacia enclaves turísticos cosmopolitas, se están generando construcciones del territorio que merecen la atención y que muestran un diálogo que va más allá de los Estados binacionales. En Pucón y Puerto Varas (Zunino e Hidalgo, 2010), por señalar algunos en Chile, y en Argentina en San Martín de los Andes, Villa La Angostura, El Bolsón, Villa General Belgrano y Puerto Madryn, que son ejemplos de receptores de este tipo de migración (Gonzalez et al., 2009; Nakayama y Arrechea 2011), se comienzan a materializar nuevas áreas de intercambio en esas zonas.

Las formas de expansión de esos asentamientos no escapan de lo vivido por las grandes áreas metropolitanas y ciudades cabeceras regionales, donde el sector inmobiliario genera una morfología de crecimiento en base a superficies con ciertos dispositivos de seguridad, como condominios y barrios cerrados que son replicados en estos asentamientos (para el caso de Buenos Aires, ver Vidal Koppmann, 2007; y para Santiago ver Hidalgo, 2004). Ellos dan cuenta de un diálogo casi permanente más allá de las estructuras políticas y que confirman la hipótesis aquí expuesta de la porosidad de la frontera y del desarrollo regional diferenciado en ciertas actividades, como del turismo y sus servicios asociados por parte del lado argentino y chileno. 


\section{Dinámica poblacional: una interpretación intercensal del espacio fronterizo binacional}

Durante la década de los ochenta nos encontramos con una frontera de baja porosidad, en Chile se produce una crisis económica particularmente fuerte; asimismo, se mantiene la represión política iniciada en 1973, período violento que en Argentina sucedió entre 1976 y 1983. Durante los noventa, las relaciones bilaterales mejoran con el retorno a la democracia en Chile.

Los datos censales muestran un intenso crecimiento poblacional en los departamentos argentinos durante los ochenta, mientras que las comunas chilenas ostentan crecimientos menores y algunas de ellas decrecimiento de su población. Enfocándonos particularmente en el análisis estadístico, el crecimiento intercensal, correspondiente al primer período 1980-1990 (Cuadro $N^{\circ} 1$ ), presenta valores que oscilan entre extremos de un $62,94 \%$ para el departamento de más crecimiento (Los Lagos, en Neuquén-Argentina) y un -12,98\% para el decrecimiento más pronunciado de la región registrado por la comuna chilena de Curarrehue, en Chile.

Junto con el departamento de Los Lagos, cuya ciudad primada es Villa La Angostura, un crecimiento alto se registra también en el departamento rionegrino de Bariloche, donde se ubica la localidad más populosa de la región bajo estudio, San Carlos de Bariloche, y también la pequeña localidad de El Bolsón. Cabe resaltar el aumento de población de este departamento en términos absolutos ya que alcanza un total de 34.000 habitantes en su crecimiento intercensal, el valor máximo en ambos períodos. En Argentina se produce un acentuado crecimiento poblacional en las localidades de tradición o potencial turístico, lo cual, en un primer nivel de análisis, estaría asociado a una estructura social que permite el desarrollo de actividades terciarias como el turismo, en especial en el contexto económico y político de los ochenta. De hecho, durante esta década, Bariloche se consolida como un destino turístico de primer orden de alcance internacional. Asimismo, González et al. (2009) destacan a las localidades de San Martín de los Andes, Villa La Angostura, El
Bolsón y Villa General Belgrano como receptoras de migrantes de amenidad asociados a emprendimientos turísticos e inmobiliarios de distinto tipo y envergadura, lo cual sugiere que la estructura social argentina gatilla procesos migratorios no convencionales más temprano que en Chile. Podemos inferir que ante un escenario de crisis, el negocio inmobiliario-turístico puede ser un espacio para el refugio para el capital (nacional y extranjero), dado que la baja del precio del suelo de espacios con atractivos singulares pasan a ser apetecidos por inversionistas que buscan rentabilidad más a largo plazo. No es de extrañar, tampoco, que las comunas que más crecieron en Chile fueron Puerto Varas y Pucón, las cuales constituyen nodos de desarrollo turístico de alcance internacional.

Asimismo, podemos distinguir un segundo grupo con aumentos medios altos y medios, cuyos valores son superiores al $15 \%$ e inferio res al $45 \%$. Allí se encuentran las unidades espaciales de Loncopué $(32,84 \%)$, luego siguen Aluminé, Hualaihué (primera comuna chilena que más ha crecido en esta región en este período), Huiliches, Futaleufú, Minas, Ñorquin, Puerto Varas, Lacar y Cushamen. Se trata en su gran mayoría de departamentos y comunas con muy escasa población, cuyos crecimientos relativos si bien son altos, deben ser analizados considerando al mismo tiempo sus magros valores absolutos. Los casos de Huiliches y Aluminé muestran una relación con el crecimiento de localidades con cierto grado de desarrollo en el turismo, como son Junín de los Andes y el eje Aluminé- Villa Pehuenia, respectivamente. El caso de Futaleufú se explica por el peso de su ciudad cabecera, Esquel, que aporta casi el $80 \%$ del total de la población del departamento y tiene también una actividad económica estrechamente vinculada al turismo.

Cabe resaltar el conjunto de comunas chilenas que han mostrado valores negativos para este período, el contexto fronterizo y de aislamiento han definido una condición expulsora de población durante este decenio. Se debe recordar que durante esta década la dictadura militar en Chile se mantenía y la aplicación del modelo neoliberal de su gobierno agravó las condiciones de desventaja de estas comunas que no pudieron retener a sus habitantes. En contrapartida, los departa- 
Cuadro $\mathrm{N}^{\circ} 1$

Crecimiento intercensal en comunas chilenas y departamentos argentinos, según región y provincia, 1980-2002

\begin{tabular}{|c|c|c|c|c|c|c|c|}
\hline $\begin{array}{l}\text { Departamento/ } \\
\text { Comuna }\end{array}$ & $\begin{array}{l}\text { Provincia/ } \\
\text { Región }\end{array}$ & \begin{tabular}{|l} 
Crecimiento \\
$1991-1980$
\end{tabular} & $\begin{array}{l}\text { Crecimiento } \\
\text { absoluto }\end{array}$ & $\begin{array}{l}\text { Departamento/ } \\
\text { Comuna }\end{array}$ & $\begin{array}{l}\text { Provincia/ } \\
\text { Región }\end{array}$ & \begin{tabular}{|l} 
Crecimiento \\
$1991-2002$
\end{tabular} & $\begin{array}{l}\text { Crecimiento } \\
\text { absoluto }\end{array}$ \\
\hline Los Lagos & Neuquén & 62,94 & 1.615 & Los Lagos & Neuquén & 106,98 & 4.473 \\
\hline Bariloche & Río Negro & 56,86 & 34.306 & Pucón & La Araucanía & 47,03 & 6.751 \\
\hline Loncopué & Neuquén & 32,84 & 1.287 & Lacar & Neuquén & 44,40 & 7.585 \\
\hline Aluminé & Neuquén & 28,74 & 1.104 & Huiliches & Neuquén & 31,21 & 3.021 \\
\hline Hualaihué & Los Lagos & 28,59 & 1.802 & Aluminé & Neuquén & 27,54 & 1.362 \\
\hline Huiliches & Neuquén & 28,20 & 2.129 & Villarrica & La Araucanía & 26,94 & 9.664 \\
\hline Futaleufú & Chubut & 28,16 & 6.764 & Minas & Neuquén & 26,81 & 1.495 \\
\hline Minas & Neuquén & 27,74 & 1.211 & Puerto Varas & Los Lagos & 24,06 & 6.383 \\
\hline Ñorquín & Neuquén & 23,46 & 786 & Loncopué & Neuquén & 24,03 & 1.251 \\
\hline Puerto Varas & Los Lagos & 21,52 & 4.698 & Cushamen & Chubut & 23,40 & 3.249 \\
\hline Lacar & Neuquén & 20,38 & 2.892 & Futaleufú & Chubut & 21,95 & 6.758 \\
\hline Cushamen & Chubut & 16,31 & 1.947 & Bariloche & Río Negro & 16,05 & 15.186 \\
\hline Futrono & Los Ríos & 14,57 & 1.787 & Curarrehue & La Araucanía & 13,48 & 806 \\
\hline Pucón & La Araucanía & 14,04 & 1.767 & Lonquimay & La Araucanía & 12,51 & 1.138 \\
\hline Picunches & Neuquén & 13,72 & 701 & Ñorquín & Neuquén & 11,90 & 492 \\
\hline Villarrica & La Araucanía & 8,78 & 2.894 & Picunches & Neuquén & 10,58 & 615 \\
\hline Lago Ranco & Los Ríos & 6,06 & 598 & Panguipulli & Los Ríos & 10,31 & 3.111 \\
\hline Languiñeo & Chubut & 5,40 & 170 & Futrono & Los Ríos & 6,64 & 933 \\
\hline Río Bueno & Los Ríos & 3,76 & 1.195 & Melipeuco & La Araucanía & 5,93 & 315 \\
\hline Chaitén & Los Lagos & 3,42 & 240 & Futaleufú & Los Lagos & 5,24 & 91 \\
\hline Panguipulli & Los Ríos & $-0,10$ & -30 & Hualaihué & Los Lagos & 2,09 & 169 \\
\hline Puyehue & Los Lagos & $-2,14$ & -245 & Puyehue & Los Lagos & 1,44 & 161 \\
\hline Cochamó & Los Lagos & $-3,05$ & -137 & Cochamó & Los Lagos & 0,05 & 2 \\
\hline Futaleufú & Los Lagos & $-4,09$ & -74 & Chaitén & Los Lagos & $-1,02$ & -74 \\
\hline Melipeuco & La Araucanía & $-5,01$ & -280 & Río Bueno & Los Ríos & $-1,07$ & -354 \\
\hline Lonquimay & La Araucanía & $-6,14$ & -595 & Lago Ranco & Los Ríos & $-3,46$ & -362 \\
\hline Curarrehue & La Araucanía & $-12,98$ & -892 & Languiñeo & Chubut & $-9,15$ & -304 \\
\hline
\end{tabular}

Fuente: Elaboración propia en base a los censos nacionales argentinos y chilenos.

mentos argentinos se mostraron con un fuerte dinamismo, especialmente aquellos destinos turísticos que ofrecían puestos de trabajo y cierta estabilidad política a partir de 1983 (ver Figura $\mathrm{N}^{\circ} 2$ ).

En Chile, con la excepción de Pucón y Puerto Varas, los crecimientos de las comunas norpatagónicas y colindantes a grandes lagos muestran un escaso incremento poblacional, asociado a la crisis económica que afectó con fuerza a las áreas de tradición productiva agropecuaria, dada la competencia de los productos importados. 
En cuanto al período correspondiente a la década del noventa (Figura $\mathrm{N}^{\circ} 2$ ), se muestra, en principio, una tendencia en la cual los departamentos y comunas de fuerte vocación turística experimentan crecimientos muy acelerados. Tal son los casos de Los Lagos, que repite su primacía como departamento con mayor crecimiento alcanzando a duplicar su población (106\%); la comuna de Pucón, donde se ubica la localidad homónima, con un 47\%; y Lácar (departamento donde se encuentra la localidad de San Martín de los Andes) con un $44 \%$. Estas tres unidades espaciales ostentan la categoría superior de crecimiento.

En cuanto a las unidades espaciales que pierden población, se destaca Languiñeo en Chubut con un $-9 \%$ y las comunas chilenas de Lago Ranco, Río Bueno y Chaitén con valores entre $-1 \%$ y $3 \%$. El departamento chubutense se encuentra muy escasamente poblado y su economía se basa en la ganadería ovina de tipo extensiva. Bariloche, si bien muestra un aumento de población, disminuye en su importancia relativa. Esta es una etapa en la cual la atracción de su localidad cabecera deja de tener el vigor de la década anterior, en especial como fuente de mano de obra para migrantes laborales.

En Chile, las comunas de Villarrica, Puerto Varas y Pucón muestran un dinamismo creciente, no tan solo por nuevos emprendimientos turísticos, sino también por la llegada de "migrantes por estilo de vida", que Zunino e Hidalgo (2010) relacionan con familias e individuos que buscan reinventar las bases de su existencia terrenal. Estamos, por tanto, en una segunda fase del crecimiento turístico en Chile. Mientras que la primera estuvo fuertemente marcada por el aumento de la oferta turística, la segunda se relaciona también con la llegada de individuos citadinos, nacionales y extranjeros, que le dan un carácter cosmopolita a estos asentamientos.

\section{Extranjeros y su rol en el crecimiento poblacional}

La montaña encierra una serie de mitos y misterios que han cruzado la historia de

Figura $\mathrm{N}^{\circ} 2$

Crecimiento de la población. Patagonia chileno-argentina, 1980-2002

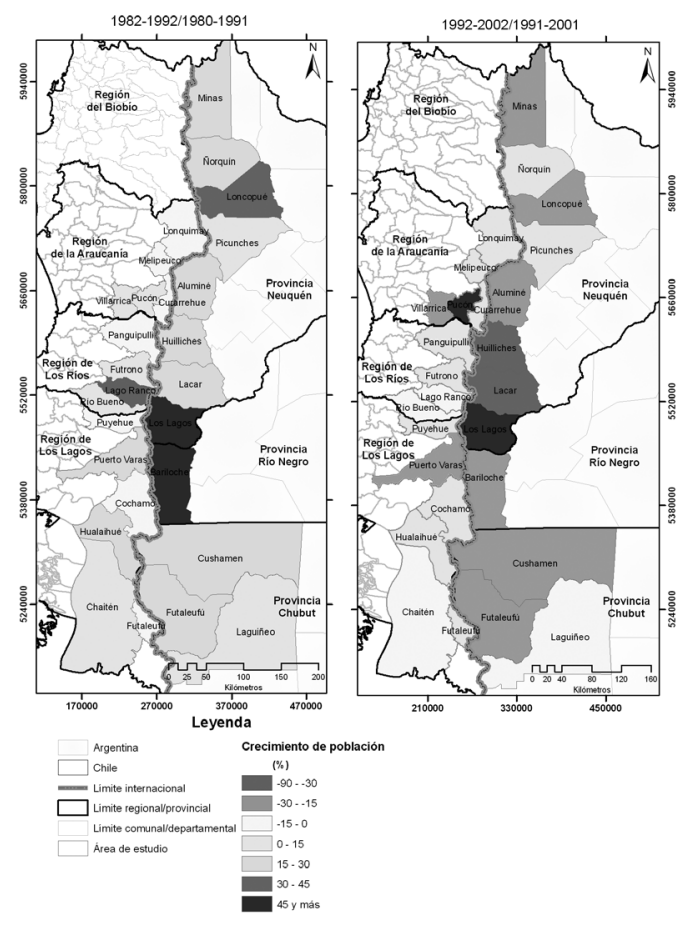

Fuente: Elaborado en base a los censos nacionales de población de Chile y Argentina. 
la humanidad, asimismo ha impulsado una gama de expresiones culturales y el desarrollo de asentamientos humanos. Al mismo tiempo, esta se erige como el hito más visible de las sinuosidades de la superficie terrestre y ha sido barrera natural y demarcadora de espacios con diferentes condiciones de habitabilidad (Hidalgo y Zunino, 2011:54). La historia de la Patagonia está hecha de relatos de viajeros, pioneros e inmigrantes. También hoy esta región, la más extensa y menos poblada de Argentina, recibe miles y miles de turistas del mundo, $y$ hasta inversores que arriban para buscar un destino a sus ingentes capitales, beneficiados por las políticas de la globalización (Sassone et al., 2010). La Patagonia chilena es el segundo espacio más despoblado de Chile, después de la zona del desierto de Atacama, en el extremo norte del país. En forma similar a lo que sucede allende los Andes, particularmente durante los últimos 20 años, se han desarrollado destinos turísticos que, a su vez, se han convertido en receptores de migrantes. Nos referimos, en particular, a asentamientos como Pucón y varios emprendimientos privados de envergadura que están cambiando el paisaje en lugares puntuales de la XIV región de Los Ríos y en la carretera austral en la X Región de Los Lagos.
La atracción migratoria de las ciudades y pueblos norpatagónicos se vincula no solo con oportunidades económicas y laborales de la región, también se suma la vigencia de un imaginario colectivo de una vida tranquila, segura y en contacto con la naturaleza.

Al intentar buscar explicaciones que nos ayuden a comprender la naturaleza de estos crecimientos demográficos, se propone estudiar la presencia de extranjeros en las unidades espaciales examinadas. Así se calcularon los valores relativos de población extranjera en relación a la población total de las comunas y departamentos. En primer lugar debemos destacar una característica que trasciende el espacio bajo estudio: Argentina ha tenido históricamente un rol receptor en la dinámica migratoria sudamericana. De allí que los valores registrados para los departamentos argentinos superen en rasgos generales aquellos de las comunas chilenas. Considerando esta salvedad, se destacan tendencias dignas de prestarle atención (Figura $N^{\circ} 3$ ).

En la Figura $\mathrm{N}^{\circ} 3$ se presentan los resultados para los tres censos analizados y se han ordenado las unidades espaciales de modo decreciente, según la importancia de la po-

Figura $\mathrm{N}^{\circ} 3$

Población extranjera: Patagonia chileno-argentina, 1980-2002
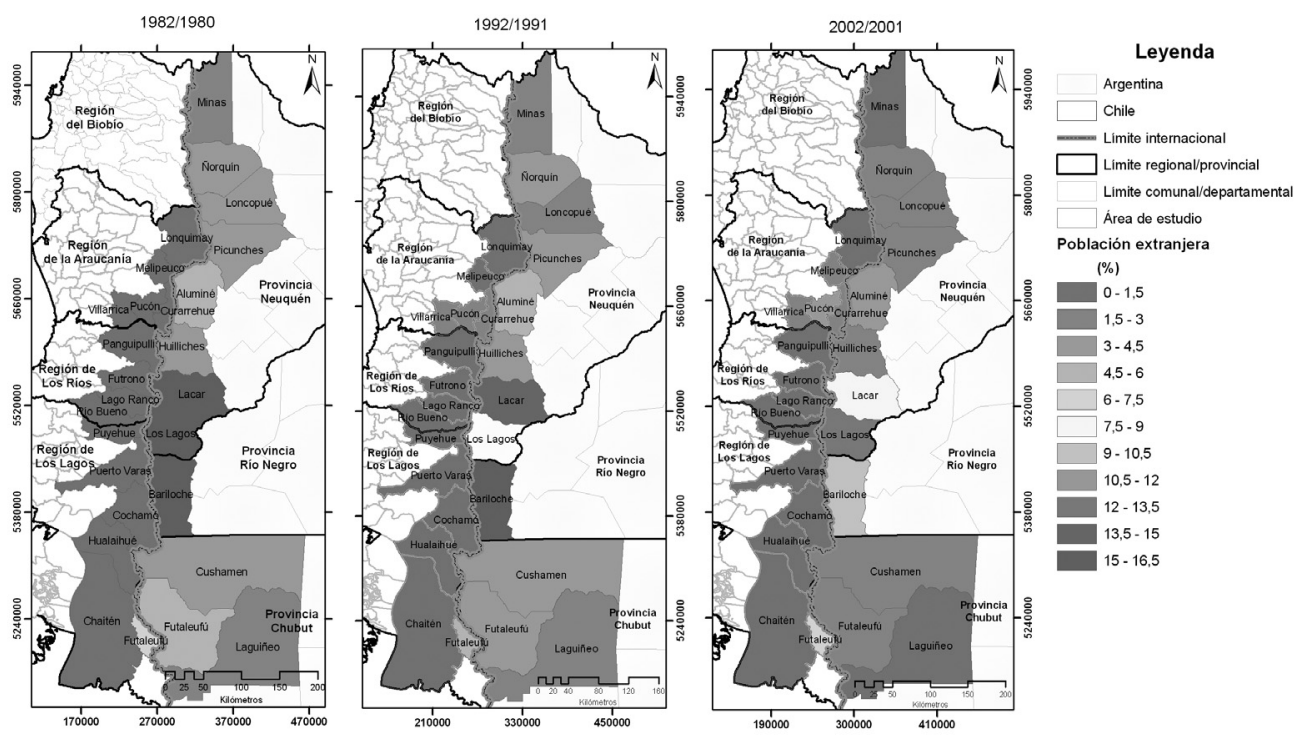

Fuente: Elaborado en base a los censos nacionales de población de Chile y Argentina. 
blación nacida en otros países. A lo largo de las tres décadas se destacan los departamentos turísticos de Bariloche, Lacar y Los Lagos con los valores más altos de porcentaje de extranjeros, con máximos en 1980 del 16\%, descendiendo muy levemente la importancia relativa de este subgrupo hacia 1991 y con más intensidad hacia 2001. En cuanto a las comunas chilenas se distingue un caso muy particular, Futaleufú, la única unidad espacial que se acerca a los valores de los departamentos argentinos y se mantiene así a lo largo del período. Este hecho se relaciona con el carácter "poroso" de la frontera en este sector (Baeza, 2007).

Fuera de este caso se registra un aumento de la importancia de la población nacida en otros países a lo largo de los tres censos en los casos de Pucón y Villarica, que pasaron del 1 al $3 \%$ entre 1982 y 2002. Si bien no se trata de un aumento significativo en términos estadísticos generales, es importante en el contexto de la poca tradición receptora de migración internacional de estas comunas.

Los crecimientos intensos guardan relación con el atractivo que poseen las localidades turísticas, aunque desde escalas y motivaciones distintas. Disímiles, según las etapas y niveles espaciales de las ciudades que conforman los departamentos y comunas. Las ciudades grandes de la Norpatagonia son ciudades jóvenes, cuya expansión se dio en el último cuarto del siglo XX. Los recursos naturales, los paisajes prístinos, el ambiente relativamente más preservado, han pesado más que la hostilidad propia de su clima o el aislamiento relativo en el momento de atraer poblaciones. Sus poblaciones urbanas son hoy verdaderos mosaicos sociales, con gentes venidas de distintos puntos del país (Sassone et al., 2010).

El caso paradigmático de esta diversidad migratoria, con mosaicos sociales complejos, es la ciudad de San Carlos de Bariloche, provincia de Río Negro (Matossian, 2010 y 2012). Esta urbe ha mostrado un intenso dinamismo demográfico a lo largo de su historia; la presencia chilena ha acompañado su devenir ya que forma parte del nacimiento de la ciudad cuando aún era un incipiente poblado. A los chilenos se sumaron pobladores de origen alemán también arribados desde el sur de
Chile hacia fines del siglo XIX y principios del XX. A partir de la segunda mitad del siglo pasado, las corrientes internacionales estuvieron casi exclusivamente compuestas por población nacida en Chile. Esta corriente tuvo otros momentos de impulso: uno de ellos posterior a la caída del gobierno de Salvador Allende, en 1973, que se mantuvo durante buena parte de dicha década y otro a principios de los ochenta. A este grupo se sumaron argentinos nativos de otras provincias, de origen tanto rural como urbano.

Vale la pena destacar la heterogeneidad de estas migraciones internas, tanto por su lugar de origen como por su perfil sociocultural. Aunque cada uno de estos grupos estuvo motivado por estímulos disímiles, el impulso procedió de la atracción como centro turístico internacional, con las consecuentes actividades económicas que de ello se desprenden, sumado a su paisaje natural y a su condición de localidad cabecera de la región de los lagos andino patagónicos argentinos, todos elementos atractivos. Entre los migrantes internos se destacan aquellos procedentes del interior de la provincia de Río Negro, especialmente de las pequeñas localidades que componen la Línea Sur de Río Negro (Pilcaniyeu, Comallo, Clemente Onelli, Ingeniero Jacobacci, Maquinchao, entre otras). A ese grupo se sumaron migrantes internos, provenientes de grandes ciudades, entre los que sobresalen los nacidos en la ciudad de Buenos Aires, en la provincia homónima, en las provincias de Neuquén, Chubut, Córdoba y Santa Fe (Matossian, 2010).

Sin embargo, es interesante preguntarnos acerca de la composición de esta población extranjera en toda el área bajo estudio.

Para el caso argentino, si reconocemos que el flujo de población chilena hacia Argentina ha disminuido a partir de la década del noventa, cabe abrir el interrogante acerca de los "nuevos" extranjeros en los pueblos y ciudades de la región. En consonancia con este hecho, se encuentran los estudios sobre "extranjerización" de la Norpatagonia (Matossian, 2008, 2012), que si bien se relaciona con elementos vinculados a la tenencia de grandes extensiones de tierra, también tiene su correlato urbano altamente relacionado con los emprendimientos inmobiliarios $y$ hoteleros 
de elite. Para el caso chileno, el fenómeno es novedoso y presenta un rumbo particular.

Esta tendencia en el cambio de los orígenes que conforman este subgrupo de la población podrá ser confirmada cuando se encuentren disponibles los nuevos datos de los censos 2011 y 2012.

\section{Consideraciones finales}

El proceso de poblamiento fue examinado a partir de los datos censales disponibles. La información sobre incremento poblacional a nivel de comuna chilena o departamento argentino se analizó tomando como referencia el marco con los contextos sociopolíticos existentes a uno y otro lado de la cordillera. Esta forma de encarar la investigación denota nuestro interés por comprender los procesos de poblamiento concatenados con las restricciones y posibilidades que impone el contexto social. Asimismo, si bien reconocemos las tensiones intrínsecas en las fronteras, asumimos una mirada más amplia reconociendo que estos espacios singulares retienen -incluso ante situaciones de tensión o conflicto- su papel como lugares de encuentro, intercambio y tránsito económico y cultural.

En efecto, incluso durante las crisis económicas y en periodos en que el ejercicio del poder ha estado concentrado en gobiernos autoritarios y represivos -como es el caso de Argentina hasta 1983 y Chile durante toda esa década-, en la década de los ochenta se observa, en general, un decrecimiento del contingente poblacional de las comunas chilenas y un crecimiento selectivo de los departamentos argentinos. Esta situación se explica tanto por la crisis económica que afectó tempranamente a Chile así como la migración política asociada a la represión y violación de los derechos humanos. Como se ha demostrado, San Carlos de Bariloche constituye un caso paradigmático al respecto. Si bien el control fronterizo se hizo más estricto, no pudo detener el éxodo de un contingente poblacional significativo hacia Argentina. El hecho de que los chilenos constituyan el principal conjunto de extranjeros en toda la Norpatagonia (Sassone y De Marco, 1994; Matossian, 2008, 2012), viene a corroborar esta situación.
Durante la década de los noventa, la dinámica poblacional tiende a equipararse con un crecimiento significativo de comunas turísticas como Pucón, Villarrica y Puerto Varas que vieron incrementos relativamente importantes en su contingente poblacional, impulsado, en el caso de las comunas de Pucón, Villarrica y Puerto Varas, por un aumento de la actividad turística, la constitución de ciudades modernas y cosmopolitas y la consiguiente migración de amenidad de población chilena y extranjera. Este último punto se constata particularmente en la comuna de Pucón. Al analizar el aumento relativo de la población extranjera en esta comuna, se colige un proceso incipiente de asentamiento de población extranjera en comunas turísticas, fenómeno incipiente que creemos se mantendrá en el tiempo y extenderá a otras comunas como Puerto Varas. En el lado argentino, el incremento poblacional de Bariloche se modera y nuevos destinos turísticos asociados con la migración de amenidad cobran relevancia: es el caso de Villa La Angostura (Departamento de Los Lagos). Asimismo, proporcionalmente la población extranjera en el lado argentino (mayoritariamente chilenos) tiende a disminuir.

Un desafío latente es examinar el desempeño del turismo durante épocas de crisis económica, política y/o institucional y cómo este puede constituirse en refugio ante las crisis de sobreacumulación o recesiones propias del funcionamiento capitalista. Para los inversionistas con mirada de mediano-largo plazo la inversión inmobiliaria en destinos turísticos puede ser una opción rentable. Más aún, no solo la concebimos como una simple estrategia económica, sino también espacial: el capital territorializa espacios singulares que les permite asegurar sus inversiones en el contexto de una sociedad consumista ávida por apropiarse utilitariamente de los pocos parajes exóticos y prístinos que van quedando.

Esto se reafirma con el crecimiento demográfico del departamento argentino de Bariloche en los ochenta $-y$ la consiguiente consolidación de la ciudad de Bariloche como centro turístico de categoría mundial- y del departamento de Los Lagos en los noventa. Si bien la dinámica poblacional es mucho menos intensa en el lado chileno, el crecimiento de las ciudades de Pucón y Puerto Varas es indicativo del mismo proceso. 
Más aún, quisiéramos abrir el lado cultural al argumento sobre la relación entre capitalismo y turismo: si bien en una primera fase estamos en presencia de una apropiación netamente utilitaria-funcional, en una segunda fase se encuentran elementos de una apropiación simbólica; vale decir, para muchos individuos el espacio se transforma en un lugar no solo para residir, sino para reinventar su vida, lo cual se enmarca en lo que en la literatura especializada se denomina migración por estilos de vida. Esto ya ha sido documentado para ciudades como Villarrica y Pucón en Chile y San Martín de Los Andes y Villa La Angostura, en Argentina. Esto nos lleva a distinguir dos ejes que merecen atención analítica futura en términos de políticas de desarrollo: el eje Comuna de Pucón y Currarehue -Departamento de Los Lagos y el de Bariloche- Puerto Varas. Estas localidades están funcionalmente ligadas y su potencial de desarrollo se fortalecería mediante estrategias binacionales que contemplen la historia compartida de estos espacios y el vigor que el turismo imprime en estos destinos.

Este estudio general ofrece las bases para sugerir nuevas líneas de investigación a escalas más acotadas. En primer lugar, resulta necesario realizar estudios en unidades territoriales menores, identificando tipos de migrantes, trayectorias residenciales, lugares de origen y de acogida. Asimismo, resulta importante acercarse binacionalmente al estudio de migración de amenidad y, más importante aún, por estilos de vida, dado que representan situaciones contraculturales que estarían marcando un contrapunto a la apropiación meramente utilitaria del territorio. La Norpatagonia representa un lugar único en el mundo, cuyo estudio se debe abordar con celeridad por investigadores locales para asegurar un desarrollo territorial armónico, preservar ambientes naturales prístinos y controlar la urbanización impulsada por la industria del turismo.

\section{Referencias bibliográficas}

AGUIRRE, J. Desarrollo local en contextos metropolitanos. Polis, 2009, № 22. Disponible en Internet: http://polis.revues.org/2622
ALEGRÍA, T. Metrópolis Transfronteriza. Revisión de la hipótesis y evidencias de Tijuana, México, y San Diego, Estados Unidos. México: Colef-Porrua, 2011.

ALLEN, A. La interfase periurbana como escenario de cambio y acción hacia la sustentabilidad del desarrollo. Cuadernos del Cendes, 2003, N 53, p.1-12.

ALLEN, A.; DA SILVA, N. \& CORUBOLO, E. Environmental problems and opportunities of the peri- urban interface and their impact upon the poor. London: The Development Planning Unit, Draftfor Discussion Papers, 1999.

ARROYO, M. La dinámica de las áreas metropolitanas en un contexto de desindustrialización. Revista de Geografía Norte Grande, 2001, N²8, p. 57-64.

BAEZA, B. El proceso de fronterización en Patagonia Central. Chilenos argentinizados y argentinos chilenizados en los pasos fronterizos de Futaleufú y Coyhaique (1885-2007). Buenos Aires: Tesis Doctoral de antropología, Facultad de Filosofía y Letras, Universidad de Buenos Aires, 2007 (Inédito).

BAEZA, B. Frontera/s y memoria/s. "Los pioneros" coyhaiquinos y trevelinenses. Intersecciones en Antropología, 2009, № 10, p. 203-219.

BAEZA, B. "Patriotas" y extranjeros en la frontera de Patagonia Central chileno-argentina. El caso de Trevelin (Argentina) y Futaleufú (Chile). Si Somos americanos. Revista de Estudios Transfronterizos, 2011, Vol. XI, p. $41-62$.

BANDIERI, S. O. Historia de la Patagonia. Buenos Aires: Editorial Sudamericana, 2005.

BARDAJÍ, I.; RAMOS, E. y RAMOS, F. Los nuevos espacios rurales. Papeles de Economía, 2008, No 117, p. 13-29.

BARSKY, A. El periurbano productivo, un espacio en constante transformación. Introducción al estado del debate, con referencias al caso de Buenos Aires. Scripta Nova. Revista electrónica de Geografía y Ciencias Sociales, 1 de agosto de 2005, Vol. IX, Nº 194 (36). Dis- 
ponible en Internet: http://www.ub.es/geocrit/ sn/sn-194-36.htm

BERNAL MEZA, R. Política exterior regional y las relaciones con Argentina. En: ARTAZAR, M. y MILET, P. (Editores). Nuestros Vecinos. Santiago de Chile: RIL Editores, 2007, p. 19-32.

BONDEL, C.S. Transformaciones territoriales y análisis geográfico en ámbitos patagónicos de montaña. La Comarca Andina del Paralelo 14. La Plata: Tesis Doctoral en Geografía, Facultad de Humanidades y Ciencias de la Educación, Universidad Nacional de La Plata, 2008 (Inédito).

CABRERA, S. Relaciones interétnicas y cuestiones limítrofes en el espacio fronterizo de la Norpatagonia. Rupturas y continuidades durante el proceso de conformación de los Estado-nación argentino y chileno. III Jornadas de Historia de la Patagonia (San Carlos de Bariloche), del 6 al 8 de noviembre de 2008 (CD ROM).

CANALES, A. Migración y trabajo en la era de la globalización: el caso de la migración México - Estados Unidos en la década de 1990. Papeles de Población, 2002, № 33, p. 48-81.

DURAND, J. y MASSEY D. Clandestinos. Migración México-Estados Unidos en los albores del siglo XXI. México: Universidad Autónoma de Zacatecas-Miguel Ángel Porrúa, 2003.

FERRÁS, C. Ciudad dispersa, aldea virtual y revolución tecnológica. Reflexión acerca de sus relaciones y significado social. Scripta Nova. Revista Electrónica de Geografía y Ciencias Sociales, 2000, Vol. 69, № 68. Disponible en Internet: http://www.ub.edu/geocrit/sn-6968.htm

FUENTES LAZO, O. Chile y la Argentina: una relación especial. En: ARTAZAR, M. y MILET, P. (Editores). Nuestros Vecinos. Santiago de Chile: RIL Editores, 2007, p. 51-60.

GIDDENS, A. The constitution of society: Outline of the theory of structuration. London: Polity Press, 1984.
GONZÁLEZ, R.; OTERO, A.; NAKAYAMA, L. y MARIONI, S. Las movilidades del turismo y las migraciones de amenidad: problemáticas y contradicciones en el desarrollo de centros turísticos de montaña. Revista de Geografía Norte Grande, 2009, № 44, p. 75-92.

HARVEY, D. Breve historia del neoliberalismo. Madrid: Akal, 2007.

HIDALGO, R. De los pequeños condominios a la ciudad vallada: las urbanizaciones cerradas y la nueva geografía social en Santiago de Chile (1990-2000). EURE, 2004, Vol. $30, N^{\circ} 91$, p. 29-52.

HIDALGO, R.; BORSDORF, A. y PLAZA, F. Parcelas de agrado alrededor de Santiago y Valparaíso: ¿Migración por amenidad a la chilena?. Revista de Geografía Norte Grande, 2009, No 44, p. 93-112.

HIDALGO, R. y ZUNINO, H.M. Negocios inmobiliarios en centros turísticos de montaña y nuevos modos de vida: El papel de los migrantes de amenidad existenciales en la Comuna de Pucón - Chile. Estudios y perspectivas en turismo, 2011, Vol. 20, №2, p. 307-326.

INSTITUTO NACIONAL DE ESTADÍSTICAS (INE). Chilenos en el exterior. Dónde viven, cuántos son y qué hacen los chilenos en el exterior. Santiago de Chile: Dirección para la Comunidad de Chilenos en el Exterior, Ministerio de Relaciones Exteriores, 2005.

KROPFF CAUSA, L. De cómo paisanos y chilotes devienen vecinos. Migración, identidad y estado en San Carlos de Bariloche. Buenos Aires: Tesis de Licenciatura en Ciencias Antropológicas, Facultad de Filosofía y Letras, Universidad de Buenos Aires, 2001 (Inédito).

LACOSTE, P. Mapas territoriales e imagen del país vecino: el caso de Argentina y Chile. En: BANDIERI, S. (Coordinador). Cruzando la cordillera. La frontera argentino-chilena como espacio social. Neuquén: Universidad Nacional del Comahue, 2001, p. 191-229.

LOLICH, L.; VEJSBJERG, L. y PONTE, J.R. Evolución de un territorio binacional históricamente compartido y su recomposi- 
ción a partir de nuevas prácticas sociales. En: NAVARRO FLORIA, P. y DELRÍO, W. (Compiladores). Cultura y espacio. Araucanía Norpatagonia. Evolución de un territorio binacional históricamente compartido y su recomposición a partir de nuevas prácticas sociales. San Carlos de Bariloche: Instituto de Investigaciones en Diversidad Cultural y Procesos de Cambio, Universidad Nacional de Río Negro, 2001, 77-91.

MAGUID, A. Migración y fronteras. La migración internacional reciente en Argentina. Asociación Latinoamericana de Sociología, 1998, p. 25-50.

MÁRMORA, L. Las regulaciones migratorias y políticas de migración en Argentina. Revista Argentina de Política Económica y Social, 1984, № 1, p. 97-109.

MATOSSIAN, B. Migración chilena en la Argentina: aproximación geográfica a partir de fuentes censales. Revista de Estudios Trasandinos. Revista de la Asociación ChilenoArgentina de Estudios Históricos e Integración Cultural, 2008, Vol. 14, № 1, p. 43-63.

MATOSSIAN, B. Expansión urbana y migración. El caso de los migrantes chilenos en San Carlos de Bariloche como actores destacados en la conformación de barrios populares. Scripta Nova. Revista Electrónica de Geografía y Ciencias sociales, 2010, Vol. XIV, № 331 (76). Disponible en Internet: http://www. ub.es/geocrit/sn/sn-331/sn-331-76.htm.

MATOSSIAN, B. Migración y segregación urbana en ciudades medias. Chilenos en San Carlos de Bariloche, Patagonia - Argentina. Berlín: Editorial Académica Española, 2012.

MÉNDEZ, L.M. Una región y dos ciudades. Puerto Montt y Bariloche; una historia económica compartida. Pueblos y Fronteras de la Patagonia Andina. Revista de Ciencias Sociales, 2005 , Vol. 5, № 5, p. 4-11.

MÉNDEZ, L.M. y TOZZINI, A. De especialidades y temporalidades en la Norpatagonia andina. Algunos aportes para su construcción y estudio. En: NAVARRO FLORIA, P. y DELRíO, W. (Compiladores). Cultura y espacio. Araucanía Norpatagonia. Evolución de un territorio binacional históricamente compartido y su recomposición a partir de nuevas prácticas sociales. San Carlos de Bariloche: Instituto de Investigaciones en Diversidad Cultural y Procesos de Cambio, Universidad Nacional de Río Negro, 2011, p. 158-171.

MONCLÚS, F. Suburbanización y nuevas periferias. Perspectivas geográfico urbanísticas. En: MONCLÚS, F. (Compilador). La Ciudad Dispersa. Barcelona: Centro de Cultura Contemporánea, 1998, p. 5-15.

MOOS, L. The amenity migration phenomenon, why it is happening and our response. In: Conferencia International Amenity Migration Centre, Kaslo, BC, 2005.

MOSS, L. (Editor). The Amenity Migrants: Seeking and Sustaining Mountains and their Cultures. Cambridge: Wallingford Press, 2006.

NAKAYAMA, L. y ARRECHEA, V. Migración de amenidad en destinos de playa. Estudio de caso: Puerto Madryn (Chubut). Anuario de Estudios en Turismo de la Universidad del Comahue, 2011, №11, p. 105-122.

NAVARRO FLORIA, P. y DELRÍO, W. Introducción. En: NAVARRO FLORIA, P. y DELRíO, W. (Compiladores). Cultura y espacio. Araucanía Norpatagonia. Evolución de un territorio binacional históricamente compartido y su recomposición a partir de nuevas prácticas sociales. San Carlos de Bariloche: Instituto de Investigaciones en Diversidad Cultural y Procesos de Cambio, Universidad Nacional de Río Negro, 2011, p. 8-14.

NORAMBUENA, C. Exilio y retorno. Chile 1973-1994. En: GARCÉS, M.; MILOS, P.; OLGUÍN, M.; PINTO, J.; ROJAS, M.T. y URRUTIA, M. (Compiladores). Memoria para un nuevo siglo. Chile, miradas a la segunda mitad del siglo XX. Santiago de Chile: LOM editores, 2000, p. 173-187.

NÚÑEZ, A. Discursos territoriales fuertes y débiles: ¿tensión o coexistencia? Chile, Siglos XIX-XX. En: NAVARRO FLORIA, P. y DELRÍO, W. (Compiladores). Cultura y espacio. Araucanía Norpatagonia. Evolución de un territorio binacional históricamente compartido y su recomposición a partir de nuevas prácticas sociales. San Carlos de Bariloche: Instituto de Investigaciones en Diversidad 
Cultural y Procesos de Cambio, Universidad Nacional de Río Negro, 2011a, p. 28-39.

NúÑEZ, A. Territorios fronterizos, territorios aislados: conceptos dinámicos de construcción histórica (procesos de significación). En: ARENAS, F.; SALAZAR, A. y NÚÑEZ, A. (Editores). El aislamiento geográfico: ¿problema u oportunidad? Experiencias, Interpretaciones y Políticas Públicas. Santiago de Chile: Serie GEOlibros, Instituto de Geografía, Universidad Católica de Chile, 2011b.

O'REILLY, K. The British on the Costa del Sol. London: Routledge, 2000.

O'DONNELL, G. El Estado Burocrático Autoritario. Buenos Aires: Editorial de Belgrano, 1982.

OSTROM, E. An agenda for the study of institutions. Public Choice, 1986, N 48, p. 3-24.

PAÍS, M. Identidades y conflictos en las ciudades de frontera. Avá. Revista de Antropología, 2011, № 18, p. 149-161.

PAREDES, A. Las prácticas políticas de los exiliados chilenos en Mendoza y su incidencia en Chile (1970-1989). Revista UNIVERSUM, 2003, No 18 .

PÉREZ, E. Hacia una nueva visión de lo rural. En: GIARRACCA, N. (Compilador). ¿Una nueva ruralidad en América Latina? Buenos Aires: CLACSO, 2001, p. 17-29.

RAMOS, J.M. Gobiernos locales y la cooperación transfronteriza México-Estados Unidos. Estudios sobre Estado y Sociedad, 2002, Vol. IX, N²5, p. 107-140.

ROMERO, L.A. La crisis argentina: una mirada al siglo XX. Buenos Aires: Siglo XXI Editores, 2003.

SALAZAR BURROWS, A. y OSSES MCINTYRE, P. La ruralidad en la Región Metropolitana de Santiago de Chile (2002): determinación y relación con los grupos socioprofesionales. Scripta Nova. Revista Electrónica de Geografía y Ciencias Sociales, 2008, Vol. XII, No 270 (112). Disponible en Internet: http://www.ub.es/geocrit/sn/sn-270/ sn-270-112.htm
SANTOS, L. Matrimonios anglos y mexicanos en la frontera. Hermosillo: El Colegio de México, 2004.

SASSONE, S.M. Migraciones ilegales y amnistías en la Argentina. En: Estudios Migratorios Latinoamericanos, 1987, Año 2, No 6/7, p. 249-290.

SASSONE, S.M. Capítulo 3. El nuevo proceso inmigratorio manifestaciones territoriales del cambio. En: DE MARCO, G.; REY BALMACEDA, R.C. y SASSONE, S.M. Extranjeros en la Argentina. Pasado, presente y futuro. Revista GEODEMOS, 1994, № 2, p. $103-136$

SASSONE, S.M. Problemática geodemográfica en las fronteras interiores del MERCOSUR: una mirada desde el territorio argentino. Anales GAEA Sociedad Argentina de Estudios Geográficos-Homenaje al Dr. Raúl Rey Balmaceda, 2002, Tomo 21-22, Vol. II (1997-2001), p. 213-246.

SASSONE, S.M. y DE MARCO, G. Capítulo 5. Problemáticas territoriales. Asentamientos y dinámica de la inmigración limítrofes. En: DE MARCO, G.; REY BALMACEDA, R.C. y SASSONE, S.M. Extranjeros en la Argentina. Pasado, presente y futuro. Revista GEODEMOS, $1994, N^{\circ} 2$, p. $179-297$.

SASSONE, S.M.; GONZÁLEZ, M.S. y MATOSSIAN, B. Ciudades patagónicas de la Argentina: atracción, crecimiento y diversidad migratoria. Aristas, 2010, № 6 .

SWYNGEDOUW, E. Neither global nor local: "Glocalization" and the politics of scale. In: COX, K.R. (Compilador). Spaces of globalization. London: Routledge, 1997, p. 137-166.

TORRADO, S. Estructura social de la Argentina: 1945-1983. Buenos Aires: Ediciones de la Flor, 1992.

ZUNINO, H.M. Power relations in urban decision making: neoliberalism, techno-politicians, and authoritarian redevelopment in Santiago. Urban Studies, 2006a, No 43, p. 1825-1846. 
ZUNINO, H.M. Construyendo ciudad desde lo local en lo global: el caso del Proyecto Ribera Norte, Concepción, Chile En: HORACIO, C. y HIDALGO, R. (Editores). Construyendo la ciudad del siglo XXI. Retos y perspectivas en España y Chile. Santiago de Chile: Serie Geolibros-Pontificia Universidad Católica, 2006b, p. 373-384.

ZUNINO, H.M. Reconstruyendo Espacios Urbanos en Santiago y Concepción: Una Lectura desde la Geografía Social Contemporánea. Investigaciones Geográficas, 2006c, Nº 14 , p. 35-49.

ZUNINO, H.M. e HIDALGO, R. Spatial and Socioeconomic Effects of Social Housing Policies Implemented in Neoliberal Chile: The Case of Valparaíso. Urban Geography, 2009, Vol. 30, N 5, p. 514-542.
ZUNINO, H.M. e HIDALGO, R. En busca de la utopía verde: migrantes de amenidad en la comuna de Pucón, IX Región de La Araucanía, Chile. Scripta Nova, Revista Electrónica de Geografía y Ciencias Sociales, 2010, Vol. XIV, No 331(75). Disponible en Internet: http://www.ub.edu/geocrit/sn/sn-331/sn-33175.htm.

ZUNINO, H.M. e HIDALGO, R. La producción multi-escalar de la periferia urbana de las áreas metropolitanas de Valparaíso y Santiago, Chile. Elementos conceptuales y analíticos. Boletín de la Asociación de Geógrafos Españoles, 2011, № 55, p. 7-33.

ZUSMAN, P. Geografías Históricas y fronteras. En: LINDÓN, A. y HIERNAUX, D. (Directores). Tratado de Geografía Humana. México: Editorial Anthropos, 2006, p. 170-186. 